\title{
Development of polyurethane-based passive samplers for ambient monitoring of urban-use insecticides in water $^{\text {is }}$
}

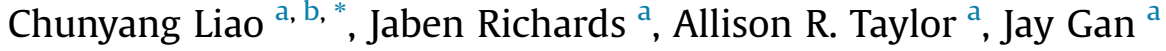 \\ a Department of Environmental Sciences, University of California, Riverside, CA 92521, United States \\ b State Key Laboratory of Environmental Chemistry and Ecotoxicology, Research Center for Eco-Environmental Sciences, Chinese Academy of Sciences, \\ Beijing 100085, China
}

\section{A R T I C L E I N F O}

\section{Article history:}

Received 16 June 2017

Received in revised form

9 August 2017

Accepted 1 September 2017

Available online 20 September 2017

\section{Keywords:}

Passive sampler

Ambient monitoring

Pyrethroids

Fipronils

Stable isotope calibration

Performance reference compound

\begin{abstract}
A B S T R A C T
Widespread use of insecticides for the control of urban pests such as ants, termites, and spiders has resulted in contamination and toxicity in urban aquatic ecosystems in different regions of the world. Passive samplers are a convenient and integrative tool for in situ monitoring of trace contaminants in surface water. However, the performance of a passive sampler depends closely on its affinity for the target analytes, making passive samplers highly specific to the types of contaminants being monitored. The goal of this study was to develop a passive sampler compatible with a wide range of insecticides, including the strongly hydrophobic pyrethroids and the weakly hydrophobic fipronil and organophosphates. Of six candidate polymeric thin films, polyurethane film (PU) was identified to be the best at enriching the test compounds. The inclusion of stable isotope labeled analogs as performance reference compounds (PRCs) further allowed the use of PU film for pyrethroids under non-equilibrium conditions. The PU sampler was tested in a large aquarium with circulatory water flow, and also deployed at multiple sites in surface streams in southern California. The concentrations of pesticides derived from the PU sampler ranged from 0.5 to $18.5 \mathrm{ng} / \mathrm{L}$, which were generally lower than the total chemical concentration measured by grab samples, suggesting that suspended particles and dissolved organic matter in water rendered them less available. The influence of suspended particles and dissolved organic matter on bioavailability was more pronounced for pyrethroids than for fipronils. The results show that the developed PU film sampler, when coupled with PRCs, may be used for rapid and sensitive in-situ monitoring of a wide range of insecticides in surface water.
\end{abstract}

() 2017 Elsevier Ltd. All rights reserved.

\section{Introduction}

Pesticides are an extremely diverse group of man-made chemicals. Many studies show that pesticide use in agriculture contributes to non-point source pollution to surface water via runoff and ground water contamination through leaching (Aravinna et al., 2017; Houbraken et al., 2017; Reichenberger et al., 2007). In recent years, an increasing number of studies also suggest that pesticide use, especially the use of insecticides for structural pest control around homes, results in contamination of surface aquatic systems in urban regions (Gan et al., 2012; Jorgenson et al., 2013; Maruya et al., 2016). Monitoring of urban-use insecticides in

\footnotetext{
* This paper has been recommended for acceptance by Maria Cristina Fossi.

* Corresponding author. Department of Environmental Sciences, University of California, Riverside, CA 92521, United States.

E-mail address: cyliao@rcees.ac.cn (C. Liao).
}

ambient water represents an ongoing challenge because of the distinct physicochemical properties of these compounds. In the past, most monitoring programs relied on collecting discrete grab water samples at a given time point, which provides data specific only to the location or time point being sampled and may not at all reflect the actual state of contamination (Fedorova et al., 2013; Kaserzon et al., 2012). Consequently, alternative sampling methods, including passive samplers, have been developed for integrative sampling (Assoumani et al., 2013; DiFilippo and Eganhouse, 2010). Among passive samplers, thin film-based samplers are considered to be more suitable for field applications than, e.g., thin fibers, due to their durability, flexibility, and relatively large sorbent volumes (Adams et al., 2007; Allan et al., 2013; Qin et al., 2010; Reitsma et al., 2013).

Passive samplers generally employ a sorbent material allowing the partition of target analytes from water to the sorbent phase (Cui et al., 2013b). At equilibrium, the concentration in water $\left(C_{\text {water }}\right)$ is 
derived from the concentration in passive sampler ( $\left.C_{\text {sampler }}\right)$ through the use of a polymer-water partition coefficient $\left(K_{\text {sampler- }}\right.$ water). Therefore, the sensitivity of a passive sampler depends closely on its ability to enrich the target analytes from water, largely limiting a given passive sampler's usefulness to analytes of similar properties (e.g., hydrophobicity or $K_{\text {ow }}$ ). For instance, polyethylene film (PE) or silicone rubber sheet is suited for strongly hydrophobic compounds such as PAHs, PCBs and DDT, while polyacrylate-coated film or polyvinyl film is more compatible with weakly hydrophobic compounds (Lao et al., 2016; Lohmann, 2012; Muir and Lohmann, 2013; Rusina et al., 2010). The need to match specific passive samplers with target analytes is a significant bottleneck to their more widespread implementation.

The overall aim of this study was to develop a passive sampler for simultaneous monitoring of a large number of urban-use insecticides in surface water. The target compounds include eight synthetic pyrethroids, two organophosphates, and fipronil and its three biologically active metabolites. Pyrethroids and fipronil are popular current-use insecticides in regions such as California, while organophosphate insecticides diazinon and chlorpyrifos were heavily used in the recent past (Maruya et al., 2016; Smalling et al., 2013; Weston and Lydy, 2012; Weston et al., 2015). The occurrence of these insecticides in surface water has been linked to acute and chronic aquatic toxicities, especially to invertebrates (Amweg et al., 2006; Bartlett et al., 2016; Brogan and Relyea, 2017; Maul et al., 2008; Ural and Sağlam, 2005; van Wijngaarden et al., 2009). These compounds also differ greatly in their physicochemical properties, with $\log K_{\text {ow }}$ ranging from 3.81 for diazinon to 7.00 for lambda-cyhalothrin (Brogan and Relyea, 2017; Laskowski, 2002). The developed sampler was shown to be capable of detecting trace levels of these insecticides in surface streams in southern California under ambient conditions.

\section{Materials and methods}

\subsection{Chemicals}

Eight pyrethroids (fenpropathrin, lambda-cyhalothrin, bifenthrin, permethrin, cyfluthrin, cypermethrin, esfenvalerate and deltamethrin), two organophosphates (diazinon and chlorpyrifos), and fipronil and its three biologically active metabolites (desulfinyl fipronil, fipronil sulfide and fipronil sulfone, referred as fipronils hereafter), were examined in this study (Table 1). Standards of diazinon (purity 99.3\%), chlorpyrifos (99.5\%), lambda-cyhalothrin (99.5\%), bifenthrin (99\%), cyfluthrin (>98\%), and esfenvalerate (>98\%), were purchased from Chem Service (West Chester, PA). Permethrin (97\%) and cypermethrin (>98\%) were obtained from FMC (Princeton, NJ), fenpropathrin (100\%) from Valent (Walnut Creek, CA), and deltamethrin (99.6\%) from Bayer Crop Science (Research Triangle Park, NC). Fipronil (98.9\%), desulfinyl fipronil (97.8\%), fipronil sulfide (98.8\%) and fipronil sulfone (99.7\%) were obtained from the U.S. Environmental Protection Agency's National Pesticide Standard Repository (Fort Meade, MD). Isotope labeled standards (rac-cis)-Z-bifenthrin-d $d_{5}(99 \%)$ and phenoxy ${ }^{13} \mathrm{C}_{6}$-cispermethrin (99\%) were purchased from Toronto Research Chemicals (Toronto, Ontario, Canada) and Cambridge Isotope Laboratories (Andover, MA), respectively. Organic solvents, including dichloromethane, methanol, acetone and hexane, were of HPLC grade and purchased from Fisher Scientific (Pittsburgh, PA). All glassware and anhydrous sodium sulfate (10-60 mesh; Fisher Scientific) were baked at $400{ }^{\circ} \mathrm{C}$ for 4 h before use to prevent crosscontamination.

\subsection{Selection of thin films}

Through literature survey, six types of thin films were initially considered as candidate sorbents for passive samplers and their enrichment capacities for the selected insecticides were evaluated in water to determine the film best suited for all compounds. The films included polyethersulfone ( $25 \mu \mathrm{m}$ in thickness, Goodfellow, Coraopolis, PA), polycarbonate (20 $\mu \mathrm{m}$, Goodfellow), polyoxymethylene (76 $\mu \mathrm{m}$, CS Hyde, Lake Villa, IL), polydimethylsiloxane (127 $\mu \mathrm{m}$, Specialty Silicone Products, Ballston Spa, NY), polyurethane ( $381 \mu \mathrm{m}$, Acrotech, Lake City, MN), and polyvinyl chloride (50 $\mu \mathrm{m}$, Goodfellow). The films were cut to strips of $2 \times 2 \mathrm{~cm}$ and cleaned in water, methanol and then hexane, and air-dried. The film strips were subsequently placed in a $100 \mathrm{~mL}$ water containing each insecticide at $1 \mu \mathrm{g} / \mathrm{L}$. After $24 \mathrm{~h}$ of mixing, the film strips were retrieved, dried with a tissue, cut to small pieces, and extracted with $20 \mathrm{~mL}$ of acetone/hexane (1:1, v:v) by shaking for $30 \mathrm{~min}$. The extract was transferred to a $250-\mathrm{mL}$ round bottom flask. The same extraction procedure was repeated for a total of three times and the

Table 1

Selected physicochemical properties and ions monitored for target chemicals.

\begin{tabular}{|c|c|c|c|c|}
\hline Chemicals & $\begin{array}{l}\text { Water solubility } \\
(\mu \mathrm{g} / \mathrm{mL})\end{array}$ & $\log K_{\text {ow }}$ & MS/MS ions $(\mathrm{m} / \mathrm{z})$ & $\begin{array}{l}\text { Retention time } \\
(\mathrm{min})\end{array}$ \\
\hline Diazinon & $40^{\mathrm{a}}$ & $3.81^{\mathrm{b}}$ & $304>179$ & 8.8 \\
\hline Desulfinyl fipronil & 0.4 & 4.63 & $388>333$ & 9.8 \\
\hline Chlorpyrifos & 0.73 & 5.00 & $314>258$ & 11.0 \\
\hline Fipronil sulfide & 0.2 & 4.77 & $351>255$ & 11.6 \\
\hline Fipronil & 1.6 & 4.01 & $368>213$ & 11.9 \\
\hline Fipronil sulfone & 1.0 & 3.68 & $383>255$ & 13.5 \\
\hline Fenpropathrin & $1.03 \times 10^{-2}$ & 6.00 & $181>152$ & 18.1 \\
\hline Lambda-cyhalothrin & $5.0 \times 10^{-3}$ & 7.00 & $181>152$ & 19.6 \\
\hline Bifenthrin & $1.4 \times 10^{-5}$ & 6.40 & $181>166$ & 17.7 \\
\hline$d_{5}$-Bifenthrin & & & $186>171$ & 17.7 \\
\hline Permethrin & $5.50 \times 10^{-3}$ & 6.10 & $183>153$ & 21.3 \\
\hline${ }^{13} \mathrm{C}_{6}$-Permethrin & & & $189>174$ & 21.1 \\
\hline Cyfluthrin & $2.3 \times 10^{-3}$ & 5.97 & $163>127$ & 22.5 \\
\hline Cypermethrin & $4.0 \times 10^{-3}$ & 6.54 & $163>127$ & 22.7 \\
\hline PCB-209 & & & $499>428$ & 23.4 \\
\hline Esfenvalerate & $6.0 \times 10^{-3}$ & 5.62 & $167>125$ & 24.9 \\
\hline Deltamethrin & $2.0 \times 10^{-4}$ & 4.53 & $181>152$ & 25.9 \\
\hline
\end{tabular}

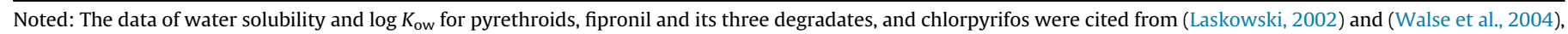
respectively.

a Data cited from (Sharom et al., 1980).

b Data cited from (Brogan and Relyea, 2017). 
combined extract was evaporated to $1 \mathrm{~mL}$ under vacuum before instrumental analysis.

\subsection{Measurement of sampler-water partition coefficients}

The above film selection test resulted in the identification of polyurethane film (PU) as the best film for the various insecticides. Subsequent method development, optimization and application experiments were therefore carried out using the PU film. To determine $K_{\text {sampler-water }}$ PU film was cut to pieces of $1.5 \times 20 \mathrm{~mm}$, and cleaned by water, methanol and hexane. After air-drying, one piece of PU film was placed in a $1 \mathrm{~L}$ water containing each pesticide at $1 \mu \mathrm{g} / \mathrm{L}$ pesticides. The solution was continuously mixed using a magnetic stirring bar. To compensate for any potential loss of pesticide adsorption to glass surfaces, the solution was renewed every 3 or $4 \mathrm{~d}$. Triplicate samples were periodically removed for analysis over a 43-d time period. The film samples were extracted with acetone/hexane $(1: 1, \mathrm{v}: \mathrm{v})$ as described above. The water phase was transferred to a glass separatory funnel and extracted with $60 \mathrm{~mL}$ of methylene chloride. The extract was passed through $20 \mathrm{~g}$ anhydrous sodium sulfate into a $500-\mathrm{mL}$ round bottom flask. The same extraction procedure was repeated for a total of three times and the extracts were condensed to $1.0 \mathrm{~mL}$ before analysis. The $K_{\text {sampler-water was estimated by fitting all } C_{\text {sampler }} \text { and } C_{\text {water }} \text { values to }}$ a first-order kinetic equation (Ai, 1997):

$y=y_{0}\left(1-e^{-k_{a b s} t}\right)$

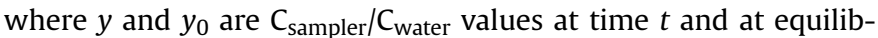

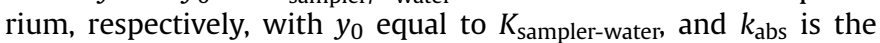
absorption rate constant.

\subsection{Use of performance reference compounds (PRCs) for pyrethroids}

Partition of pyrethroids into the PU film was found to be very slow, and an apparent equilibrium was not reached after $43 \mathrm{~d}$ of equilibration. Stable isotope labeled bifenthrin ( $d_{5}$-bifenthrin) and permethrin $\left({ }^{13} \mathrm{C}_{6}\right.$-permethrin) were used as performance reference compounds (PRCs) for calibration, so that a PU sampler may be used under non-equilibrium conditions before the partition equilibrium is reached. The use of PRCs has been previously introduced for PE samplers, polyurethane foam passive air samplers, solid-phase microextraction fibers, semipermeable membrane devices, and polar organic chemical integrative samplers (Bao et al., 2015; Belles et al., 2014; Cui et al., 2013b; Huckins et al., 2002; Iparraguirre et al., 2017; Joyce et al., 2015; Kennedy et al., 2010; Thompson et al., 2015). To preload PRCs, pieces of PU film $(1.5 \times 20 \mathrm{~mm})$ were placed in a $250-\mathrm{mL}$ glass flask with $200 \mathrm{~mL}$ acetone/water (1:4, v:v) solution containing $d_{5}$-bifenthrin and ${ }^{13} \mathrm{C}_{6}$-permethrin at $20 \mu \mathrm{g} / \mathrm{L}$ for each compound. After continuous mixing for $48 \mathrm{~h}$, the PRCimpregnated PU strips were retrieved and rinsed with water. A subset of 3 preloaded strips was randomly selected to determine the initial amount of PRCs preloaded onto the film.

Calibration using PRCs works under the assumption that kinetics of absorption of target analytes from water onto the film is similar to desorption of PRCs from the film into water, that is, absorption of target analytes and desorption of PRCs obey isotropy. A batch equilibration experiment was carried out to validate the isotropic exchange between pyrethroid absorption onto the PU film and desorption of $\mathrm{d}_{5}$-bifenthrin and ${ }^{13} \mathrm{C}_{6}$-permethrin from the film. Absorption of pyrethroids onto the PU film may be described as ( $\mathrm{Ai}$, 1997): $n=n_{0}\left(1-e^{-k_{a b s} t}\right)$

where $n$ and $n_{0}$ are the amounts of pyrethroids absorbed onto the PU film at time $t$ and at equilibrium, respectively, and $k_{\mathrm{abs}}$ is the absorption rate constant. Desorption of PRCs from the PU film may be described as (Chen and Pawliszyn, 2004; Zhou et al., 2007):

$q=q_{0} e^{-k_{\text {des }} t}$

where $q_{0}$ and $q$ are the initial amount of PRCs preloaded on the PU film and the amount remaining on the film at time $t$, respectively, and $k_{\mathrm{des}}$ is the desorption rate constant. If isotropy holds, Eqs. (2) and (3) may be combined as:

$\frac{n}{n_{0}}+\frac{q}{q_{0}}=1$

Therefore, if the sum of $n / n_{0}$ and $q / q_{0}$ is 1 at any sampling interval, the isotropy of absorption and desorption is validated, i.e., $k_{\mathrm{abs}}=k_{\text {des }}$. The freely dissolved concentration $\left(C_{\text {free }}\right)$ of pyrethroids in water may be estimated from the concentration in passive sampler $\left(C_{\text {sampler }}\right)$ through the use of $K_{\text {sampler-water }}$ under nonequilibrium condition:

$C_{\text {free }}=\frac{C_{\text {sampler }}}{K_{\text {sampler-water }}}=\frac{n /\left(1-\frac{q}{q_{0}}\right)}{M_{\text {sampler }} K_{\text {sampler-water }}}$

where $M_{\text {sampler }}$ is the mass of PU film. At a pre-set sampling interval (under non-equilibrium condition), $n_{0}$ may be obtained using Eq. (4) after $q$ and $n$ are determined for the PU film, which can then be used to calculate $C_{\text {sampler }}$, that is, $C_{\text {sampler }}=n_{0} / M_{\text {sampler }}$.

The isotropy validation experiment was conducted as follows: one piece $(1.5 \mathrm{~mm} \times 20 \mathrm{~mm})$ of PRC-preloaded PU film was placed in a glass vial containing $25 \mathrm{~mL}$ of each pyrethroid at $10 \mu \mathrm{g} / \mathrm{L}$. The solution was mixed at $120 \mathrm{rpm}$ on a horizontal shaker, and triplicate samples were removed after 1, 2.5, 4, 6, 8, 16, 24, 30, 48, 96, 144, 192 , or $288 \mathrm{~h}$ for extraction and analysis of non-labeled and isotope labeled pyrethroids, as described above.

\subsection{Laboratory simulation experiment}

The sampler performance was tested by measuring $C_{\text {free }}$ of pesticides in a large glass tank under simulated conditions. An acetone solution $(2.5 \mathrm{~mL})$ containing pesticides $(100 \mu \mathrm{g} / \mathrm{mL}$ each $)$ was spiked into a $280 \mathrm{~L}$ glass aquarium containing $250 \mathrm{~L}$ of water to arrive at an initial nominal concentration of $1 \mu \mathrm{g} / \mathrm{L}$ for each pesticide. The PRC-preloaded PU strips $(5 \times 50 \mathrm{~mm})$ were suspended in the middle of the aquarium using a steel wire. A pump was used to circulate the water at a constant velocity. Three PU samplers were retrieved at 2,4 , or $8 \mathrm{~d}$ after the deployment and three water samples $(0.5 \mathrm{~L})$ were simultaneously collected at each sampling interval. The PU samplers were extracted and analyzed for the target pesticides as described above. The water samples were simultaneously extracted and analyzed to derive the total chemical concentration.

\subsection{Field applications}

The performance of PU samplers was further tested under field conditions. The PRC-preloaded PU strips $(5 \times 50 \mathrm{~mm})$ were secured with fishing hooks in parallel in a stainless steel mesh cage (Fig. S1; Supplementary Material), and the cages were deployed at multiple points (sites WC1, WC3, SC2, and SC3) in small surface streams 
draining urban neighborhoods in Orange County, California in May 2015 (Fig. S2). The PU samplers were retrieved after 4 d. Grab water samples ( $1 \mathrm{~L})$ were simultaneously collected at the sample locations before the deployment and at the time the PU samplers were retrieved. The retrieved PU samplers and grab water samples were transported on ice to the laboratory and stored at $4{ }^{\circ} \mathrm{C}$ before analysis.

\subsection{Instrumental analysis}

The identification and quantification of pesticides were performed on a Varian 3800 GC coupled with a Varian 1200 triple quadrupole mass spectrometer (GC-MS/MS; Varian, Sunnyvale, CA). An aliquot of 1 or $2 \mu \mathrm{L}$ of the final extract was injected at $240{ }^{\circ} \mathrm{C}$ in the pulsed splitless mode at 45 psi with the purge valve closed for $1.0 \mathrm{~min}$. A DB-5MS capillary column (30 $\mathrm{m} \times 0.25 \mathrm{~mm} \times 0.25 \mu \mathrm{m}$, Agilent, Wilmington, DE) was used for separation and high purity helium (99.999\%) was used as the carrier gas at a flow rate of $1.0 \mathrm{~mL} / \mathrm{min}$. The oven temperature was set at $80{ }^{\circ} \mathrm{C}$ for $1.0 \mathrm{~min}$, increased to $160{ }^{\circ} \mathrm{C}$ at $25^{\circ} \mathrm{C} / \mathrm{min}$, and then increased to $300{ }^{\circ} \mathrm{C}$ at $5{ }^{\circ} \mathrm{C} / \mathrm{min}$ and held at $300{ }^{\circ} \mathrm{C}$ for $7 \mathrm{~min}$. The MS/MS was operated in electron ionization (EI) mode at $70 \mathrm{eV}$ with multiple reaction monitoring (MRM), and the MRM transitions of ions monitored are listed in Table 1 . The transfer line, ionization source, and manifold temperatures were set at 300,250 , and $40^{\circ} \mathrm{C}$, respectively.

\subsection{Quality assurance and quality control}

All experiments were conducted in triplicates and the results were expressed as mean \pm standard deviation. External surrogate (PCB-209) was introduced into all samples before extraction to monitor extraction efficiency and instrument drift. The recovery of external surrogate was $43.2-118 \%$. Procedural blanks were included in every batch of 9-15 samples to check for potential contamination arising from experimental procedures. A midpoint calibration check standard was injected as a check for instrumental drift in sensitivity every 20 samples, and a pure solvent (hexane) was injected as a check for carry-over of analytes between samples. Multilevel calibration curves $(0.1-1000 \mu \mathrm{g} / \mathrm{L})$, covering the whole concentration ranges found in the samples, were used to quantify the analytes, and the regression coefficient $(r)$ of the calibration curve was 0.99 or above. Difference between treatments was determined by one-way analysis of variance (ANOVA) using Origin 8.6 (OriginLab; Northampton, MA), unless stated otherwise.

\section{Results and discussion}

\subsection{Evaluation of film types for broad analyte compatibility}

Six types of thin films, i.e., polyethersulfone, polycarbonate, polyoxymethylene, polydimethylsiloxane, polyurethane (PU), and polyvinyl chloride, were chosen as candidates to test their enrichment potential for eight pyrethroids, two organophosphates, and four fipronils in water. All of the six thin films have been previously used on specific groups of organic compounds (DiFilippo and Eganhouse, 2010; Fedorova et al., 2013; Genualdi et al., 2010; Gibbs et al., 2017; Kohoutek et al., 2010; Lissalde et al., 2014; Posada-Ureta et al., 2016; Shetty et al., 2014). The polyethersulfone and polycarbonate films were found to physically disintegrate after $1 \mathrm{~d}$ of mixing, so they were excluded from further testing. Additionally, no detectable amounts of pesticides were found on the polyvinyl chloride film likely due to the polar property of the film. As shown in Fig. 1, the polydimethylsiloxane film enriched pyrethroids, but not fipronils. The PU film showed high

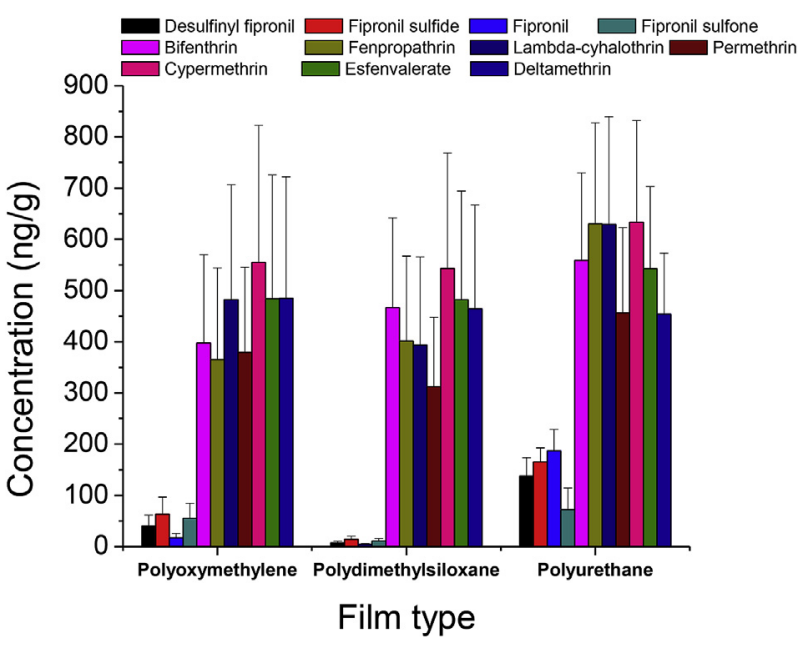

Fig. 1. Levels of pyrethroids and fipronils in different types of thin films after $24 \mathrm{~h}$ of contact.

affinity for both pyrethroids and fipronils, and the enrichment was generally greater than the polyoxymethylene film. Therefore, the PU film was selected as the film type best suited for monitoring the suite of insecticides considered in this study.

\subsection{Sampler-to-water partition coefficient ( $\left.K_{\text {sampler-water }}\right)$}

The coefficient $K_{\text {sampler-water }}$ is essential for deriving $C_{\text {free }}$ of analytes when using a passive sampler (Hunter et al., 2009; Mayer et al., 2000; Poerschmann et al., 1997). After identification of the best film, the uptake kinetics of pesticides from water to the PU film was determined. The $K_{\text {sampler-water }}$ was estimated by fitting all $C_{\text {sampler }} / C_{\text {water }}$ values to Eq. ( 1$)$. The results of regression analysis are shown in Table 2. The fit was good for the majority of target analytes $\left(r^{2}>0.70\right)$, except for diazinon $\left(r^{2}=0.38\right)$, cyfluthrin $\left(r^{2}=0.51\right)$, and cypermethrin $\left(r^{2}=0.49\right)$. There was a clear increasing trend for all pesticides in their accumulation on the PU film (Fig. 2). However, except for diazinon, fipronil, and desulfinyl fipronil, the other pesticides did not appear to have reached equilibrium between the PU strip and water even after $43 \mathrm{~d}$ of equilibration.

The highest $\log K_{\text {sampler-water value was found for deltamethrin }}$ (5.72), followed by, in a decreasing order, chlorpyrifos (5.07), fenpropathrin (5.02), fipronil sulfone (4.96), and fipronil sulfide (4.86).

Table 2

The kinetics parameters and regression equations of pesticides by PU film.

\begin{tabular}{llll}
\hline Chemicals & $\begin{array}{l}\text { Log } K_{\text {sampler-water }} \\
(\mathrm{RT})^{\mathrm{a}}\end{array}$ & $K_{\mathrm{abs}}$ & $r^{2}$ \\
\hline Diazinon & 2.89 & 1.21 & 0.38 \\
Desulfinyl fipronil & 4.46 & 0.127 & 0.92 \\
Chlorpyrifos & 5.07 & 0.0312 & 0.94 \\
Fipronil sulfide & 4.86 & 0.0564 & 0.89 \\
Fipronil & 3.68 & 0.321 & 0.89 \\
Fipronil sulfone & 4.96 & 0.0281 & 0.82 \\
fenpropathrin & 5.02 & 0.0929 & 0.76 \\
Lambda-cyhalothrin & 4.72 & 0.103 & 0.80 \\
Bifenthrin & 4.23 & 0.165 & 0.89 \\
Permethrin & 4.17 & 0.239 & 0.74 \\
Cyfluthrin & 3.89 & 0.301 & 0.51 \\
Cypermethrin & 3.95 & 0.500 & 0.49 \\
Esfenvalerate & 4.48 & 0.0920 & 0.92 \\
Deltamethrin & 5.72 & 0.0767 & 0.97 \\
\hline
\end{tabular}

${ }^{a}$ The $K_{\text {sampler-water }}$ values were measured at room temperature (RT). 

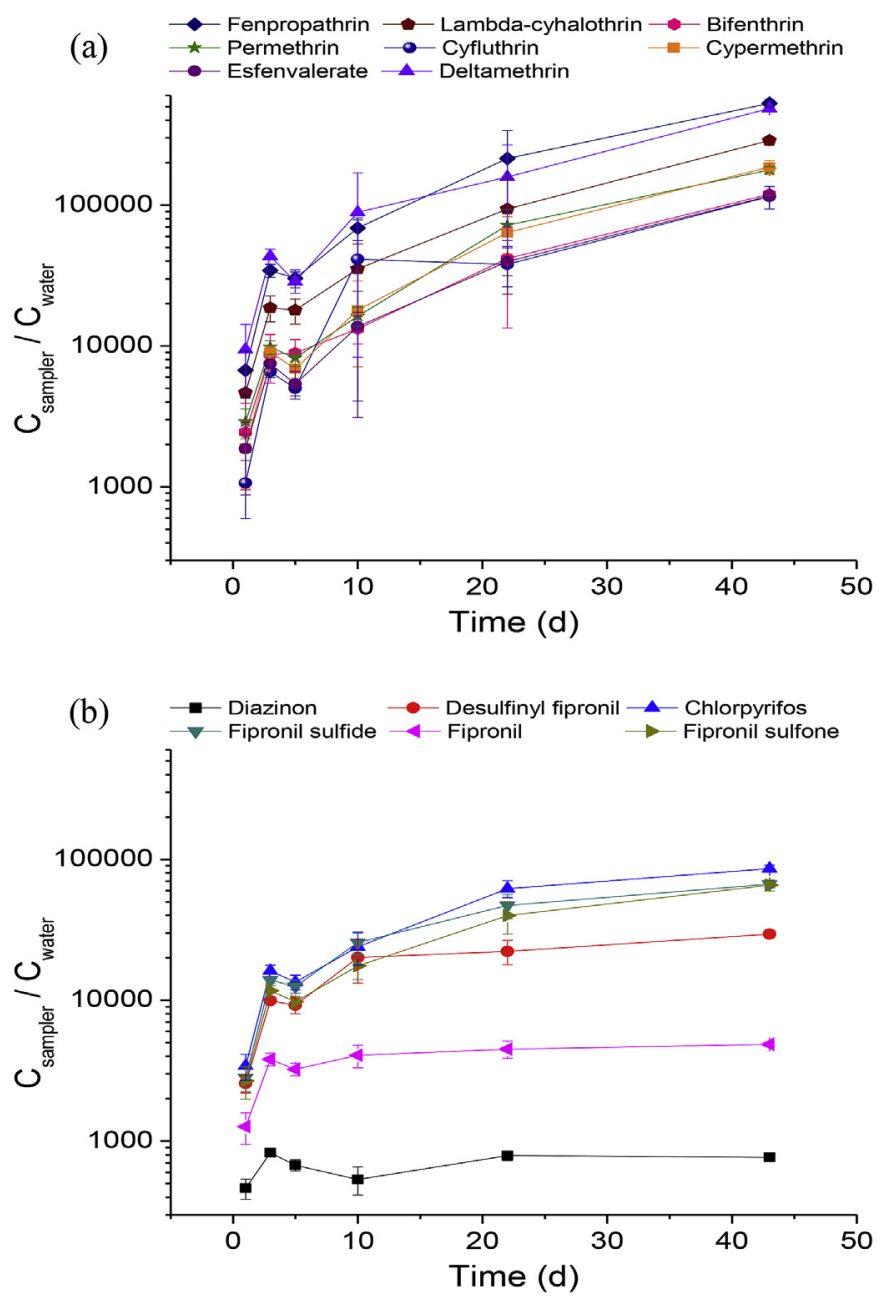

Fig. 2. Accumulation of pesticides from water onto polyurethane film over time: (a) pyrethroids; (b) organophosphates and fipronils.

Diazinon, fipronil, and cyfluthrin had lower $\log K_{\text {sampler-water }}$ values (Table 2). The results suggested that a very long time would be needed for pyrethroids to reach equilibrium in the PU film, precluding the use of PU film under equilibrium conditions and justifying the need to incorporate PRCs for the practical use of PU samplers for ambient monitoring.

\subsection{Isotropy validation}

Following the PRC preloading procedures used in this study, $4.02 \pm 1.73$ and $4.21 \pm 0.73 \mu \mathrm{g} / \mathrm{g}$ of $\mathrm{d}_{5}$-bifenthrin and ${ }^{13} \mathrm{C}_{6^{-}}$ permethrin were loaded onto the PU film, respectively. Deuterated analogue $\mathrm{d}_{5}$-bifenthrin was used as PRC for bifenthrin and ${ }^{13} \mathrm{C}_{6^{-}}$ permethrin was used as PRC for the other pyrethroids due to structural similarity. The absorption of the non-labeled pyrethroids $\left(n / n_{0}\right)$ from the spiked water was found to generally mirror the desorption of the labeled PRCs $\left(q / q_{0}\right)$ from the PU film to the bathing water (Fig. 3). The sum of $n / n_{0}$ and $q / q_{0}$ was generally in the range of $0.8-1.2$ and was not statistically different from 1 for most of the time points ( $p>0.05$, One-Sample $t$-Test). This suggests isotropy between absorption of pyrethroids onto the sampler and desorption of the isotope labeled anlogues from the PU film into water. In a previous study, good isotropy was also observed for pyrethroids between polydimethylsiloxane fiber and water (Cui et al., 2013a). The results suggested that the PU sampler, if coupled with PRCs, may be used under non-equilibrium conditions for detecting $C_{\text {free }}$ of pyrethroids in water. This is advantageous because a short, flexible sampling interval makes the use of passive samplers much more feasible for ambient monitoring.

The uptake of diazinon, chlorpyrifos, and fipronils appeared to have reached a steady state in $96 \mathrm{~h}$, as no further increases were evident thereafter (Fig. 3i). Therefore, $96 \mathrm{~h}$ (4 d) was set as the sampling time interval for all target pesticides considered in this study. The $C_{\text {free }}$ values of organophosphates and fipronils were calculated directly from $C_{\text {sampler }}$ at the time of sampling, while $C_{\text {free }}$ values of pyrethroids were estimated from Eq. (5) by using the desorption fraction of PRCs.

\subsection{Validation of passive sampler under simulated conditions}

The performance of PU thin-film sampler was first evaluated on the target pesticides under simulated conditions in a large glass tank. The total chemical concentrations $\left(C_{\mathrm{w}}\right)$ measured following solvent extraction were in the low $\mu \mathrm{g} / \mathrm{L}$ range (Table 3 ) and remained relatively constant over time ( $p>0.05$, one-way ANOVA), suggesting that sorption onto the PU sampler did not appreciably deplete the chemical pool in the system. A slight increase in the concentrations of pesticides derived from the PU thin-film passive sampler $\left(C_{\text {free, }}\right.$ which will be calculated from $C_{0} / K_{\text {sampler-water }}$; here $C_{0}$ is the concentration of pesticides on the film sampler at equilibrium) was observed (Hunter et al., 2009; Mayer et al., 2000; Poerschmann et al., 1997). As can be seen in Table 3 , the $C_{\mathrm{w}}$ values at $4 \mathrm{~d}$ were in agreement with those found for $C_{\text {free. }}$. This is due to the glass aquarium contains no suspended particles or dissolved organic matter, and thus analysis of water should give concentrations similar to $C_{\text {free. }}$. This result further validates that the assumption that isotope labeled analogues may be used as PRCs to calibrate PU sampling so that the PU thin-film passive sampler may be used under non-equilibrium conditions with flexible sampling time for the measurement of $C_{\text {free }}$ of pesticides in water (Cui et al., 2013a, b; Bao et al., 2015; Jia et al., 2014).

\subsection{Field applications}

The PU sampler was further tested under field conditions. The PRC-preloaded samplers were deployed at four locations in urban streams draining residential areas in Orange County, California. Three PU film strips $(5 \times 50 \mathrm{~mm})$ were attached to the inside of a small stainless steel mesh cage and placed in the water for $4 \mathrm{~d}$ before retrieval and analysis. Grab water samples were collected at the time of sample retrieval and analyzed for the total chemical concentrations. Fipronil and three metabolites (desulfinyl fipronil, fipronil sulfide and fipronil sulfone) were found in all water samples with a detection frequency of $100 \%$. Fipronil sulfone and fipronil were the predominant derivatives and the concentrations were in the range of 46.7-104 and 33.0-68.5 ng/L, respectively, which were slightly higher than those found for desulfinyl fipronil (23.4-29.3 ng/L) and fipronil sulfide (19.6-24.5 ng/L) (Table 4). These results showed that the concentrations of fipronils in urban runoff outfalls in Orange County, California were somewhat higher than those found in coastal urban watersheds in southern California (range of fipronil: non-detectable (n.d.)-28.7 ng/L) (Maruya et al., 2016), and several creeks near San Francisco Bay, California (fipronil: n.d.-27.4 ng/L, desulfinyl fipronil: n.d.-7.1 ng/L, fipronil sulfide: n.d.-8.4 ng/L, and fipronil sulfone: n.d.-11.9 ng/L) (Weston et al., 2015). However, these levels were lower than those previously reported from residential drainage water in Orange County, California (fipronil: 1.8-10,000 ng/L, desulfinyl fipronil: 2.4-1120 ng/L, fipronil sulfide: n.d.-330 ng/L, and fipronil sulfone: n.d.-1960 ng/L), where the total concentrations of these 
(a)

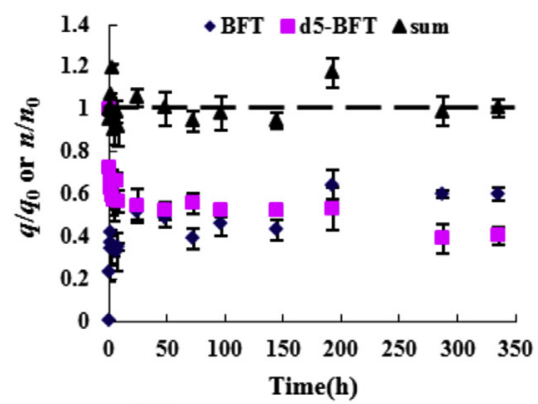

(d)

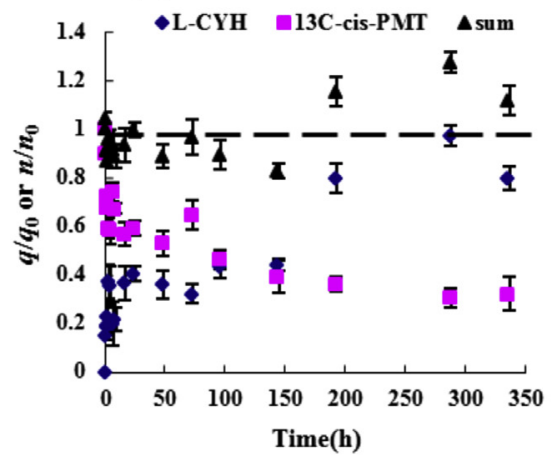

(g)

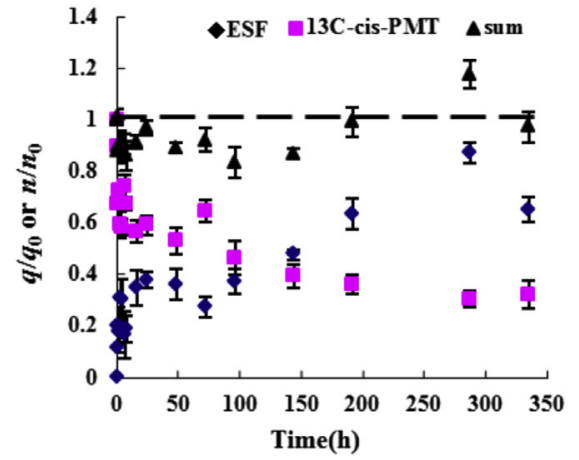

(b)

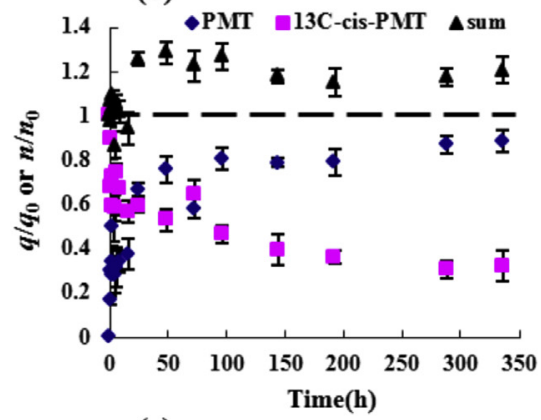

(e)

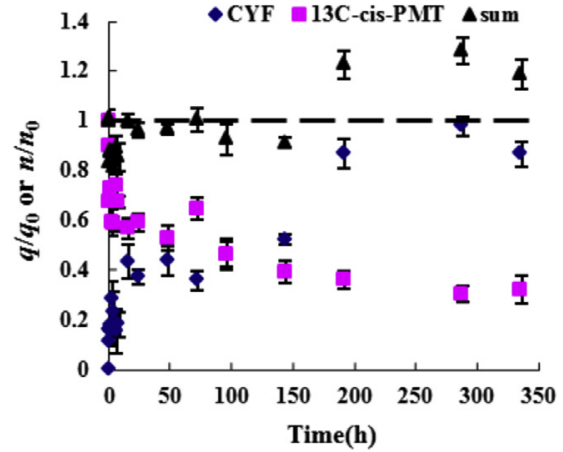

(h)

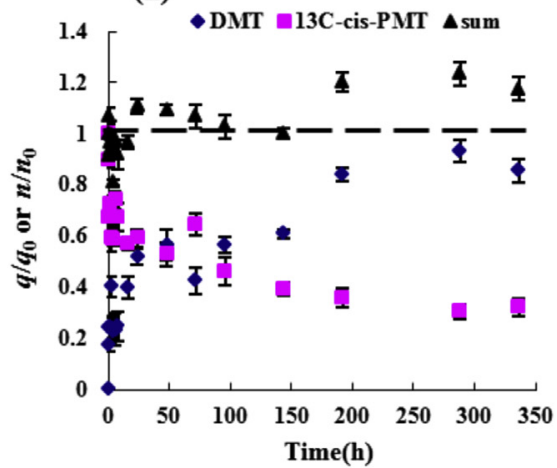

(c)

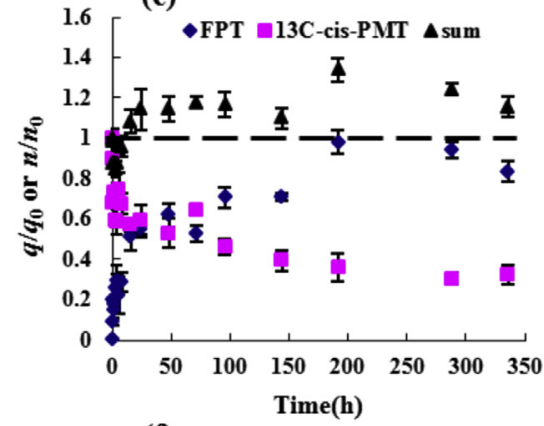

(f)

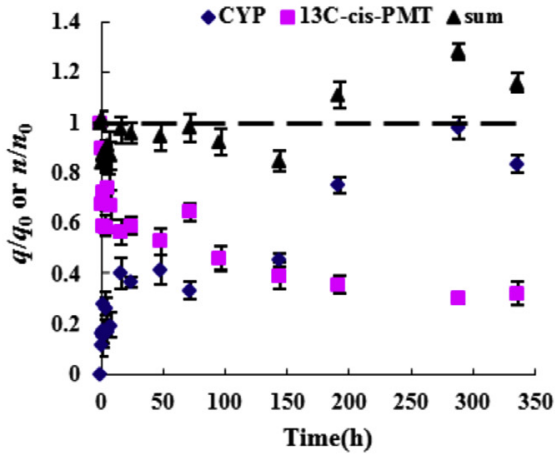

(i)

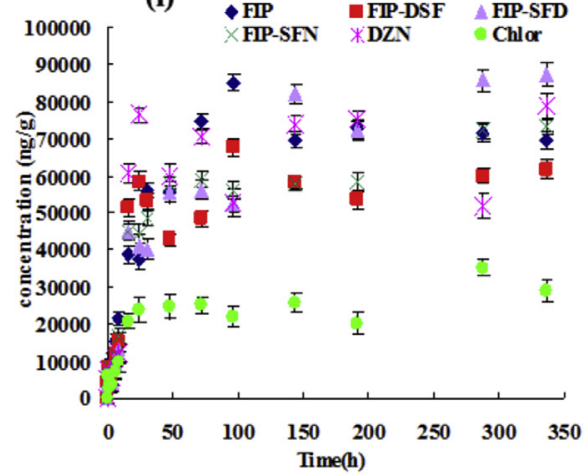

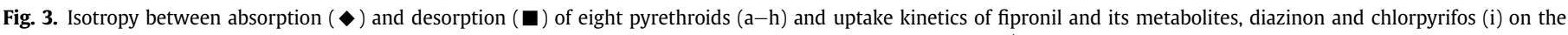

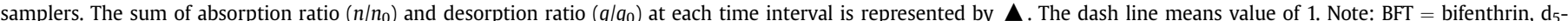

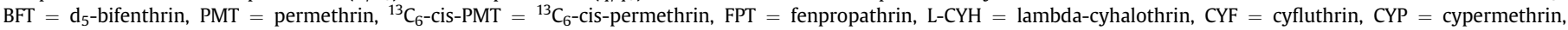

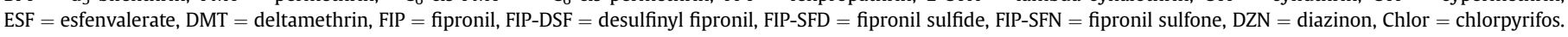

Table 3

Comparison between pesticide concentrations $(\mathrm{ng} / \mathrm{L})$ derived from the passive sampler $\left(C_{\text {free }}\right)$ and water $\left(C_{\mathrm{w}}\right)$.

\begin{tabular}{|c|c|c|c|c|c|c|}
\hline \multirow[t]{2}{*}{ Chemicals } & \multicolumn{2}{|l|}{$2 d$} & \multicolumn{2}{|l|}{$4 d$} & \multicolumn{2}{|l|}{$8 d$} \\
\hline & $C_{\text {free }}$ & $C_{\mathrm{w}}$ & $C_{\text {free }}$ & $C_{\mathrm{w}}$ & $C_{\text {free }}$ & $C_{\mathrm{w}}$ \\
\hline Diazinon & $2620 \pm 243$ & $1700 \pm 161$ & $2620 \pm 747$ & $1400 \pm 63.2$ & $2360 \pm 810$ & $1290 \pm 149$ \\
\hline Desulfinyl fipronil & $1050 \pm 207$ & $2080 \pm 223$ & $1320 \pm 1000$ & $1960 \pm 220$ & $2040 \pm 1190$ & $1870 \pm 194$ \\
\hline Chlorpyrifos & $245 \pm 49.6$ & $779 \pm 98.0$ & $257 \pm 209$ & $432 \pm 47.0$ & $311 \pm 170$ & $267 \pm 26.6$ \\
\hline Fipronil sulfide & $530 \pm 95.3$ & $2000 \pm 315$ & $724 \pm 948$ & $1940 \pm 281$ & $1260 \pm 1170$ & $1840 \pm 184$ \\
\hline Fipronil & $1670 \pm 289$ & $2320 \pm 381$ & $2420 \pm 1190$ & $2410 \pm 337$ & $3170 \pm 1560$ & $2400 \pm 193$ \\
\hline Fipronil sulfone & $417 \pm 65.1$ & $2020 \pm 462$ & $588 \pm 976$ & $2110 \pm 385$ & $1020 \pm 1320$ & $2050 \pm 175$ \\
\hline fenpropathrin & $135 \pm 18.4$ & $455 \pm 114$ & $201 \pm 167$ & $383 \pm 75.3$ & $356 \pm 140$ & $225 \pm 27.7$ \\
\hline Lambda-cyhalothrin & $64.3 \pm 8.75$ & $152 \pm 59.7$ & $100 \pm 96.1$ & $223 \pm 54.4$ & $210 \pm 116$ & $191 \pm 26.4$ \\
\hline Bifenthrin & $141 \pm 18.4$ & $114 \pm 54.8$ & $198 \pm 83.5$ & $198 \pm 52.6$ & $364 \pm 98.6$ & $169 \pm 29.2$ \\
\hline Permethrin & $368 \pm 19.6$ & $185 \pm 44.4$ & $604 \pm 110$ & $236 \pm 48.3$ & $1200 \pm 108$ & $173 \pm 19.9$ \\
\hline Cyfluthrin & $353 \pm 88.5$ & $180 \pm 50.4$ & $685 \pm 107$ & $230 \pm 40.7$ & $1280 \pm 117$ & $182 \pm 16.4$ \\
\hline Cypermethrin & $297 \pm 77.6$ & $174 \pm 39.8$ & $583 \pm 110$ & $227 \pm 33.7$ & $1100 \pm 115$ & $176 \pm 12.8$ \\
\hline Esfenvalerate & $102 \pm 9.33$ & $145 \pm 19.9$ & $169 \pm 98.1$ & $194 \pm 28.2$ & $308 \pm 106$ & $161 \pm 10.1$ \\
\hline Deltamethrin & $8.53 \pm 1.87$ & $172 \pm 20.7$ & $14.4 \pm 106$ & $211 \pm 33.0$ & $24.7 \pm 82.2$ & $159 \pm 42.3$ \\
\hline
\end{tabular}


Table 4

Comparison between pyrethroid concentrations $(\mathrm{ng} / \mathrm{L})$ derived from the passive sampler $\left(C_{\text {free }}\right)$ and water $\left(C_{\mathrm{w}}\right)$.

\begin{tabular}{|c|c|c|c|c|c|c|c|c|}
\hline \multirow[t]{2}{*}{ Chemicals } & \multicolumn{2}{|l|}{ WC1 } & \multicolumn{2}{|l|}{ WC3 } & \multicolumn{2}{|l|}{$\mathrm{SC} 2$} & \multicolumn{2}{|l|}{ SC3 } \\
\hline & $C_{\text {free }}$ & $C_{\mathrm{w}}$ & $C_{\text {free }}$ & $C_{\mathrm{w}}$ & $C_{\text {free }}$ & $C_{\mathrm{w}}$ & $C_{\text {free }}$ & $C_{\mathrm{w}}$ \\
\hline Diazinon & $\mathrm{nd}^{\mathrm{a}}$ & nd & nd & nd & nd & nd & nd & nd \\
\hline Desulfinyl fipronil & $6.02 \pm 3.23$ & $23.4 \pm 6.50$ & $5.35 \pm 1.11$ & $28.6 \pm 7.79$ & $8.10 \pm 1.89$ & $28.9 \pm 13.6$ & $4.58 \pm 0.509$ & $29.3 \pm 17.8$ \\
\hline Chlorpyrifos & nd & nd & nd & nd & nd & nd & nd & nd \\
\hline Fipronil sulfide & $4.56 \pm 2.39$ & $19.6 \pm 4.23$ & $4.36 \pm 0.848$ & $21.5 \pm 5.44$ & $6.75 \pm 1.46$ & $19.8 \pm 3.70$ & $3.75 \pm 0.369$ & $24.5 \pm 15.0$ \\
\hline Fipronil & $7.32 \pm 3.95$ & $33.0 \pm 8.58$ & $6.21 \pm 1.48$ & $44.9 \pm 13.3$ & $9.87 \pm 2.70$ & $45.4 \pm 25.1$ & $5.77 \pm 0.482$ & $68.5 \pm 68.3$ \\
\hline Fipronil sulfone & $5.83 \pm 2.12$ & $46.7 \pm 13.6$ & $6.93 \pm 0.962$ & $68.0 \pm 28.2$ & $7.11 \pm 1.33$ & $48.2 \pm 35.8$ & $3.69 \pm 0.585$ & $104 \pm 115$ \\
\hline Fenpropathrin & nd & nd & nd & nd & nd & nd & nd & nd \\
\hline Lambda-cyhalothrin & $1.50 \pm 0.461$ & $307 \pm 329$ & $1.29 \pm 0.123$ & $29.6 \pm 8.51$ & $1.69 \pm 0.410$ & $18.4 \pm 3.40$ & $2.36 \pm 1.06$ & $25.2 \pm 17.5$ \\
\hline Bifenthrin & $4.65 \pm 2.18$ & $32.2 \pm 7.21$ & $2.81 \pm 0.350$ & $30.1 \pm 8.91$ & $3.60 \pm 1.04$ & $24.8 \pm 10.8$ & $3.91 \pm 2.05$ & $96.9 \pm 58.5$ \\
\hline Permethrin & $2.74 \pm 0.934$ & $23.8 \pm 2.41$ & $2.22 \pm 0.287$ & $18.8 \pm 4.09$ & $3.20 \pm 0.634$ & $96.3 \pm 92.2$ & $2.52 \pm 0.242$ & $942 \pm 1070$ \\
\hline Cyfluthrin & $0.591 \pm 0.226$ & $23.2 \pm 3.08$ & $0.509 \pm 0.023$ & $25.9 \pm 10.4$ & $0.724 \pm 0.198$ & $24.7 \pm 4.90$ & $0.496 \pm 0.043$ & $44.8 \pm 33.0$ \\
\hline Cypermethrin & $1.31 \pm 0.600$ & $17.5 \pm 3.01$ & $1.21 \pm 0.127$ & $16.9 \pm 5.00$ & $1.64 \pm 0.265$ & $15.2 \pm 2.72$ & $1.18 \pm 0.046$ & $24.1 \pm 19.9$ \\
\hline Esfenvalerate & $4.70 \pm 1.55$ & $19.0 \pm 3.53$ & $4.10 \pm 0.601$ & $18.5 \pm 5.21$ & $5.61 \pm 0.891$ & $17.2 \pm 3.13$ & $3.81 \pm 0.509$ & $30.1 \pm 21.5$ \\
\hline Deltamethrin & $13.0 \pm 7.01$ & $44.5 \pm 5.67$ & $12.0 \pm 2.38$ & $40.2 \pm 8.40$ & $18.5 \pm 3.60$ & $39.2 \pm 6.65$ & $11.0 \pm 1.13$ & $65.3 \pm 64.4$ \\
\hline
\end{tabular}

a nd = not detected; Note: diazinon, chlorpyrifos, and fenpropathrin were not detected in both sampler and water samples.

compounds were determined in whole water samples (Gan et al., 2012).

As can be seen from Table 4, diazinon, chlorpyrifos and fenpropathrin were not detected in any of the water samples, while the other seven pyrethroids (lambda-cyhalothrin, bifenthrin, permethrin, cyfluthrin, cypermethrin, esfenvalerate, and deltamethrin) were found in all water samples with a detection frequency of $100 \%$. The mean concentration of permethrin was $270 \mathrm{ng} /$ L, which was 2-10 folds higher than those found for lambdacyhalothrin (95.1 ng/L), deltamethrin (47.3 ng/L), bifenthrin (46.0 ng/L), cyfluthrin (29.7 ng/L), esfenvalerate (21.2 ng/L) and cypermethrin $(18.4 \mathrm{ng} / \mathrm{L})$. The pyrethroid concentrations in urban runoff outfalls in Orange County, California present in this study were 1-3 orders of magnitude higher than those found for coastal urban watersheds in southern California (permethrin: n.d.-1.7 ng/L) (Maruya et al., 2016), surface streams near San Francisco Bay, California (bifenthrin: n.d.-9.9 ng/L) (Weston et al., 2015), and urban runoff to the American River in northern California (bifenthrin: n.d.-106 ng/L, cyfluthrin: n.d.-26.6 ng/L, cypermethrin: n.d.-9.4 ng/ L, permethrin: n.d.-111 ng/L) (Weston and Lydy, 2012). The elevated occurrence was likely due to heavier use of pyrethroid products in the southern California region due to warmer temperature and hence greater pest pressure.

In general, the concentrations of fipronil and its three metabolites (desulfinyl fipronil, fipronil sulfide and fipronil sulfone) derived from the PU thin-film sampler were slightly lower than those measured by the grab water samples, but the difference was not statistically significant ( $p>0.05$, one-way ANOVA, Table 4 ). This suggests that fipronil and its metabolites are moderately hydrophobic, and the presence of suspended solids and dissolved organic matter did not appreciably decrease $C_{\text {free }}$ compared to the total chemical concentration. Similarly, the pyrethroid concentrations determined by using PU thin-film sampler were slightly lower than those measured by the grab samples, while the concentrations agreed generally within one order of magnitude $(p>0.05$, one-way ANOVA, Table 4). Comparatively, the matching in concentrations of pyrethroids determined by the two manners is fairly better than that for fipronils, which may be due to pyrethroid data being PRCcorrected while fipronil data were calculated at equilibrium (no PRC-correction) (Fernandez et al., 2012).

\section{Application considerations}

Pesticides including pyrethroids and fipronil are commonly used in urban environments to control undesirable pests such as ants, termites, and spiders (Fernandez et al., 2012; Gan et al., 2012; Maruya et al., 2016; Weston and Lydy, 2012; Weston et al., 2015). Widespread use of such pesticides has caused their frequent occurrence in urban surface waters. Passive samplers (e.g. on the basis of thin-films) have been developed as novel tools for monitoring surface water contaminants. Due to discrepancy in physicochemical nature (e.g. polarity) of chemicals, it is challenging to use one type of passive sampler to detect compounds with different properties. As shown in this study, the PU thin-film passive sampler was capable of simultaneously enriching and monitoring pyrethroids, organophosphates, and fipronils in urban surface water. Comparatively, such thin-film samplers may be more suitable for field applications, due to their low-cost, durability, flexibility, and relatively large sorbent volume. The PU thin-film passive sampler therefore is promising to be used in ambient monitoring of a wide range of pesticides in surface water.

Loading of performance reference compounds (PRCs) in passive samplers enables non-equilibrium sampling, effectively removing the requirement for attaining equilibrium or steady state for highly hydrophobic compounds such as pyrethroids (Cui et al., 2013b; Bao et al., 2015; Jia et al., 2014). The loading of PRCs may provide a great benefit due to the shortened and flexible deployment time, which is important since long-term deployment may lead to potential alterations of the sampler (e.g., biofouling, physical damages, or loss of sampling device) (Cui et al., 2013a; Jia et al., 2014). In the present study, isotope-labeled analogues $\left(d_{5}\right.$-bifenthrin and ${ }^{13} C_{6}$-permethrin) were used as PRCs for pyrethroids and the PRC calibration reduced the sampling time to only $4 \mathrm{~d}$. It must be noted that many commerciallyavailable standards labeled with ${ }^{13} \mathrm{C}$ or deuterium are available nowadays and MS-equipped instruments are also commonly present in research and service laboratories. Therefore the use of stable isotope labeled standards as PRCs may greatly expand the range of applications for passive samplers on contaminants of diverse physicochemical properties, such as contemporary pesticides.

\section{Acknowledgements}

The study was funded by California Department of Pesticide Regulation. We thank Dr. Fredrick Ernst for assistance in fabrication of the thin-film passive sampler used in the field applications.

\section{Appendix A. Supplementary data}

Supplementary data related to this article can be found at https://doi.org/10.1016/j.envpol.2017.09.002. 


\section{References}

Adams, R.G., Lohmann, R., Fernandez, L.A., MacFarlane, J.K., Gschwend, P.M., 2007 Polyethylene devices: passive samplers for measuring dissolved hydrophobic organic compounds in aquatic environments. Environ. Sci. Technol. 41 (4), 1317-1323.

Ai, J., 1997. Solid phase microextraction for quantitative analysis in nonequilibrium situations. Anal. Chem. 69 (6), 1230-1236.

Allan, I.J., Harman, C., Ranneklev, S.B., Thomas, K.V., Grung, M., 2013. Passive sampling for target and nontarget analyses of moderately polar and nonpolar substances in water. Environ. Toxicol. Chem. 32 (8), 1718-1726.

Amweg, E.L., Weston, D.P., You, J., Lydy, M.J., 2006. Pyrethroid insecticides and sediment toxicity in urban creeks from California and Tennessee. Environ. Sci. Technol. 40 (5), 1700-1706.

Aravinna, P., Priyantha, N., Pitawala, A., Yatigammana, S.K., 2017. Use pattern of pesticides and their predicted mobility into shallow groundwater and surface water bodies of paddy lands in Mahaweli river basin in Sri Lanka. J. Environ. Sci Health B 52 (1), 37-47.

Assoumani, A., Lissalde, S., Margoum, C., Mazzella, N., Coquery, M., 2013. In situ application of stir bar sorptive extraction as a passive sampling technique for the monitoring of agricultural pesticides in surface waters. Sci. Total. Environ. 463-464, 829-835.

Bao, L.J., Wu, X., Jia, F., Zeng, E.Y., Gan, J., 2015. Isotopic exchange on SPME fiber in sediment under stagnant conditions: implications for field application of PRC calibration. Environ. Toxicol. Chem. 35 (8), 1978-1985.

Bartlett, A.J., Struger, J., Grapentine, L.C., Palace, V.P., 2016. Examining impacts of current-use pesticides in Southern Ontario using in situ exposures of the amphipod Hyalella azteca. Environ. Toxicol. Chem. 35 (5), 1224-1238.

Belles, A., Tapie, N., Pardon, P., Budzinski, H., 2014. Development of the performance reference compound approach for the calibration of "polar organic chemical integrative sampler" (POCIS). Anal. Bioanal. Chem. 406 (4), 1131-1140.

Brogan 3rd, W.R. Relyea, R.A., 2017. Multiple mitigation mechanisms: effects of submerged plants on the toxicity of nine insecticides to aquatic animals. Environ. Pollut. 220 (Pt A), 688-695.

Chen, Y., Pawliszyn, J., 2004. Kinetics and the on-site application of standards in a solid-phase microextraction fiber. Anal. Chem. 76 (19), 5807-5815.

Cui, X., Bao, L., Gan, J., 2013a. Solid-phase microextraction (SPME) with stable isotope calibration for measuring bioavailability of hydrophobic organic contaminants. Environ. Sci. Technol. 47 (17), 9833-9840.

Cui, X., Mayer, P., Gan, J., 2013b. Methods to assess bioavailability of hydrophobic organic contaminants: principles, operations, and limitations. Environ. Pollut. $172,223-234$

DiFilippo, E.L., Eganhouse, R.P., 2010. Assessment of PDMS-water partition coefficients: implications for passive environmental sampling of hydrophobic organic compounds. Environ. Sci. Technol. 44 (18), 6917-6925.

Fedorova, G., Golovko, O., Randak, T., Grabic, R., 2013. Passive sampling of perfluorinated acids and sulfonates using polar organic chemical integrative samplers. Environ. Sci. Pollut. Res. Int. 20 (3), 1344-1351.

Fernandez, L.A., Lao, W., Maruya, K.A., White, C., Burgess, R.M., 2012. Passive sampling to measure baseline dissolved persistent organic pollutant concentrations in the water column of the Palos Verdes shelf superfund site. Environ. Sci. Technol. 46 (21), 11937-11947.

Gan, J., Bondarenko, S., Oki, L., Haver, D., Li, J.X., 2012. Occurrence of fipronil and its biologically active derivatives in urban residential runoff. Environ. Sci. Technol. 46 (3), 1489-1495.

Genualdi, S., Lee, S.C., Shoeib, M., Gawor, A., Ahrens, L., Harner, T., 2010. Global pilot study of legacy and emerging persistent organic pollutants using sorbentimpregnated polyurethane foam disk passive air samplers. Environ. Sci. Technol. 44 (14), 5534-5539.

Gibbs, J.L., Yost, M.G., Negrete, M., Fenske, R.A., 2017. Passive sampling for indoor and outdoor exposures to chlorpyrifos, azinphos-methyl, and oxygen analogs in a rural agricultural community. Environ. Health Perspect. 125 (3), 333-341.

Houbraken, M., Habimana, V., Senaeve, D., López-Dávila, E., Spanoghe, P., 2017. Multi-residue determination and ecological risk assessment of pesticides in the lakes of Rwanda. Sci. Total Environ. 576, 888-894.

Huckins, J.N., Petty, J.D., Lebo, J.A., Almeida, F.V., Booij, K., Alvarez, D.A., Cranor, W.L. Clark, R.C., Mogensen, B.B., 2002. Development of the permeability/performance reference compound approach for in situ calibration of semipermeable membrane devices. Environ. Sci. Technol. 36 (1), 85-91.

Hunter, W., Yang, Y., Reichenberg, F., Mayer, P., Gan, J., 2009. Measuring pyrethroids in sediment pore water using matrix-solid phase microextraction. Environ. Toxicol. Chem. 28 (1), 36-43.

Iparraguirre, A., Prieto, A., Vallejo, A., Moeder, M., Zuloaga, O., Etxebarria, N. Paschke, A. 2017. Tetraphasic polar organic chemical integrative sampler for the determination of a wide polarity range organic pollutants in water. the use of performance reference compounds and in-situ calibration. Talanta 164, $314-322$.

Jia, F., Bao, L.J., Crago, J., Schlenk, D., Gan, J., 2014. Use of isotope dilution method to predict bioavailability of organic pollutants in historically contaminated sediments. Environ. Sci. Technol. 48 (14), 7966-7973.
Jorgenson, B., Fleishman, E., Macneale, K.H., Schlenk, D., Scholz, N.L., Spromberg, J.A., Werner, I., Weston, D.P., Xiao, Q., Young, T.M., Zhang, M., 2013. Predicted transport of pyrethroid insecticides from an urban landscape to surface water. Environ. Toxicol. Chem. 32 (11), 2469-2477.

Joyce, A.S., Pirogovsky, M.S., Adams, R.G., Lao, W., Tsukada, D., Cash, C.L., Haw, J.F., Maruya, K.A., 2015. Using performance reference compound-corrected polyethylene passive samplers and caged bivalves to measure hydrophobic contaminants of concern in urban coastal seawaters. Chemosphere 127, 10-17.

Kaserzon, S.L., Kennedy, K., Hawker, D.W., Thompson, J., Carter, S., Roach, A.C., Booij, K., Mueller, J.F., 2012. Development and calibration of a passive sampler for perfluorinated alkyl carboxylates and sulfonates in water. Environ. Sci. Technol. 46 (9), 4985-4993.

Kennedy, K., Hawker, D.W., Bartkow, M.E., Carter, S., Ishikawa, Y., Mueller, J.F., 2010. The potential effect of differential ambient and deployment chamber temperatures on PRC derived sampling rates with polyurethane foam (PUF) passive air samplers. Environ. Pollut. 158 (1), 142-147.

Kohoutek, J., Marsálek, B., Bláha, L., 2010. Evaluation of the novel passive sampler for cyanobacterial toxins microcystins under various conditions including field sampling. Anal. Bioanal. Chem. 397 (2), 823-828.

Lao, W., Hong, Y., Tsukada, D., Maruya, K.A., Gan, J., 2016. A New film-based passive sampler for moderately hydrophobic organic compounds. Environ. Sci. Technol. 50 (24), 13470-13476.

Laskowski, D.A., 2002. Physical and chemical properties of pyrethroids. Rev. Environ. Contam. Toxicol, 174, 49-170.

Lissalde, S., Mazzella, N., Mazellier, P., 2014. Polar organic chemical integrative samplers for pesticides monitoring: impacts of field exposure conditions. Sci. Total Environ. 488-489, 188-196.

Lohmann, R., 2012. Critical review of low-density polyethylene's partitioning and diffusion coefficients for trace organic contaminants and implications for its use as a passive sampler. Environ. Sci. Technol. 46 (2), 606-618.

Maruya, K.A., Dodder, N.G., Sengupta, A., Smith, D.J., Lyons, J.M., Heil, A.T., Drewes, J.E., 2016. Multimedia screening of contaminants of emerging concern (CECS) in coastal urban watersheds in southern California (USA). Environ. Toxicol. Chem. 35 (8), 1986-1994.

Maul, J.D., Brennan, A.A., Harwood, A.D., Lydy, M.J., 2008. Effect of sedimentassociated pyrethroids, fipronil, and metabolites on Chironomus tentans growth rate, body mass, condition index, immobilization, and survival. Environ. Toxicol. Chem. 27 (12), 2582-2590.

Mayer, P., Vaes, W.H.J., Wijnker, F., Legierse, K., Kraaij, R.H., Tolls, J., Hermens, J.L.M., 2000. Sensing dissolved sediment porewater concentrations of persistent and bioaccumulative pollutants using disposable solid-phase microextraction fibers. Environ. Sci. Technol. 34, 5177-5183.

Muir, D., Lohmann, R., 2013. Water as a new matrix for global assessment of hydrophilic POPs. Trends Anal. Chem. 46, 162-172.

Poerschmann, J., Zhang, Z.Y., Kopinke, F.D., Pawliszyn, J., 1997. Solid phase microextraction for determining the distribution of chemicals in aqueous matrices. Anal. Chem. 69, 597-600.

Posada-Ureta, O., Olivares, M., Zatón, L., Delgado, A., Prieto, A., Vallejo, A., Paschke, A., Etxebarria, N., 2016. Uptake calibration of polymer-based passive samplers for monitoring priority and emerging organic non-polar pollutants in WWTP effluents. Anal. Bioanal. Chem. 408 (12), 3165-3175.

Qin, Z., Mok, S., Ouyang, G., Dixon, D.G., Pawliszyn, J., 2010. Partitioning and accumulation rates of polycyclic aromatic hydrocarbons into polydimethylsiloxane thin films and black worms from aqueous samples. Anal. Chim. Acta 667 (1-2), $71-76$.

Reichenberger, S., Bach, M., Skitschak, A., Frede, H.G., 2007. Mitigation strategies to reduce pesticide inputs into ground- and surface water and their effectiveness; a review. Sci. Total Environ. 384 (1-3), 1-35.

Reitsma, P.J., Adelman, D., Lohmann, R., 2013. Challenges of using polyethylene passive samplers to determine dissolved concentrations of parent and alkylated PAHs under cold and saline conditions. Environ. Sci. Technol. 47 (18), 10429-10437.

Rusina, T.P., Smedes, F., Koblizkova, M., Klanova, J., 2010. Calibration of silicone rubber passive samplers: experimental and modeled relations between sampling rate and compound properties. Environ. Sci. Technol. 44 (1), 362-367.

Sharom, M.S., Miles, J.R.W., Harris, C.R., McEwen, F.L., 1980. Behaviour of 12 insecticides in soil and aqueous suspensions of soil and sediment. Water Res. 14 (8), 1095-1100.

Shetty, M.K. Limmer, M.A., Waltermire, K., Morrison, G.C., Burken, J.G., 2014. In planta passive sampling devices for assessing subsurface chlorinated solvents. Chemosphere 104, 149-154.

Smalling, K.L., Kuivila, K.M., Orlando, J.L., Phillips, B.M., Anderson, B.S., Siegler, K. Hunt, J.W., Hamilton, M., 2013. Environmental fate of fungicides and other current-use pesticides in a central California estuary. Mar. Pollut. Bull. 73 (1), $144-153$.

Thompson, J.M., Hsieh, C.H., Luthy, R.G., 2015. Modeling uptake of hydrophobic organic contaminants into polyethylene passive samplers. Environ. Sci. Technol. 49 (4), 2270-2277.

Ural, M.Ș., Sağlam, N., 2005. A study on the acute toxicity of pyrethroid deltamethrin on the fry rainbow trout (Oncorhynchus mykiss Walbaum, 1792). Pestic. Biochem. Physiol. 83, 124-131. 
van Wijngaarden, R.P., Barber, I., Brock, T.C., 2009. Effects of the pyrethroid insecticide gamma-cyhalothrin on aquatic invertebrates in laboratory and outdoor microcosm tests. Ecotoxicology 18 (2), 211-224.

Walse, S.S., Pennington, P.L., Scott, G.I., Ferry, J.L., 2004. The fate of fipronil in modular estuarine mesocosms. J. Environ. Monit. 6 (1), 58-64.

Weston, D.P., Chen, D., Lydy, M.J., 2015. Stormwater-related transport of the insecticides bifenthrin, fipronil, imidacloprid, and chlorpyrifos into a tidal wetland, San Francisco Bay, California. Sci. Total Environ. 527-528, 18-25. Weston, D.P., Lydy, M.J., 2012. Stormwater input of pyrethroid insecticides to an urban river. Environ. Toxicol. Chem. 31 (7), 1579-1586.

Zhou, S., Zhang, X., Ouyang, G., Es-haghi, A., Pawliszyn, J., 2007. On fiber standardization technique for solid-coated solid-phase microextraction. Anal. Chem. 79 (3), 1221-1230. 